\title{
Advantages of symphyseal distraction in the treatment of Brodie's Syndrome
}

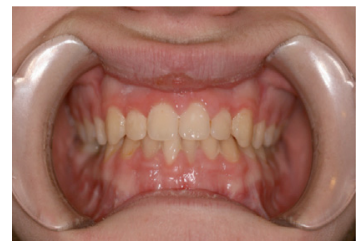

\author{
Christine SAUVÉ ${ }^{1}$, Thomas WOJCIK ${ }^{2}$, Joël FERRI ${ }^{3}$ \\ 1 Doctorate of Dental Medicine, Master's degree in Science, Fellow of the Royal College of Dentists of Canada \\ $2 M D$ \\ $3 M D, P h D$
}

\section{ABSTRACT}

Orthodontists and maxillo-facial surgeons are very aware of the different therapeutic options for the correction of maxillary transverse deficiencies. But what about mandibular transverse deficiencies? A number of dentofacial orthopedic mandibular expansion techniques have been suggested, but they often have a tendency to relapse. Symphyseal distraction is the easiest solution for the correction of mandibular transverse defects, particularly in cases of a major deficiency such as Brodie's Syndrome. In addition to recreating a physiologic occlusion, this technique makes it possible to considerably increase the width of the bony and soft tissue that not only improves the patient's function and esthetics, but also helps to ensure long-term occlusal stability as well.

\section{KEY WORDS}

Brodie's syndrome

Symphyseal distraction

Mandibular widening

\section{DEFINITION AND CLINICAL SIGNS}

Brodie's Syndrome, also known as "scissors-bite," is a transverse anomaly of the jaws. The two causes, excessive maxillary width and excessive mandibular narrowing,
Address for correspondence:

Christine SAUVÉ

CHU de Québec, Hôpital de l'Enfant Jésus, 1401

$18^{\mathrm{e}}$ rue, Québec (QC),

Canada G1J 1 Z4

chsauve1234@gmail.com
Article received: 03-2013. Accepted for publication: 05-2013. 


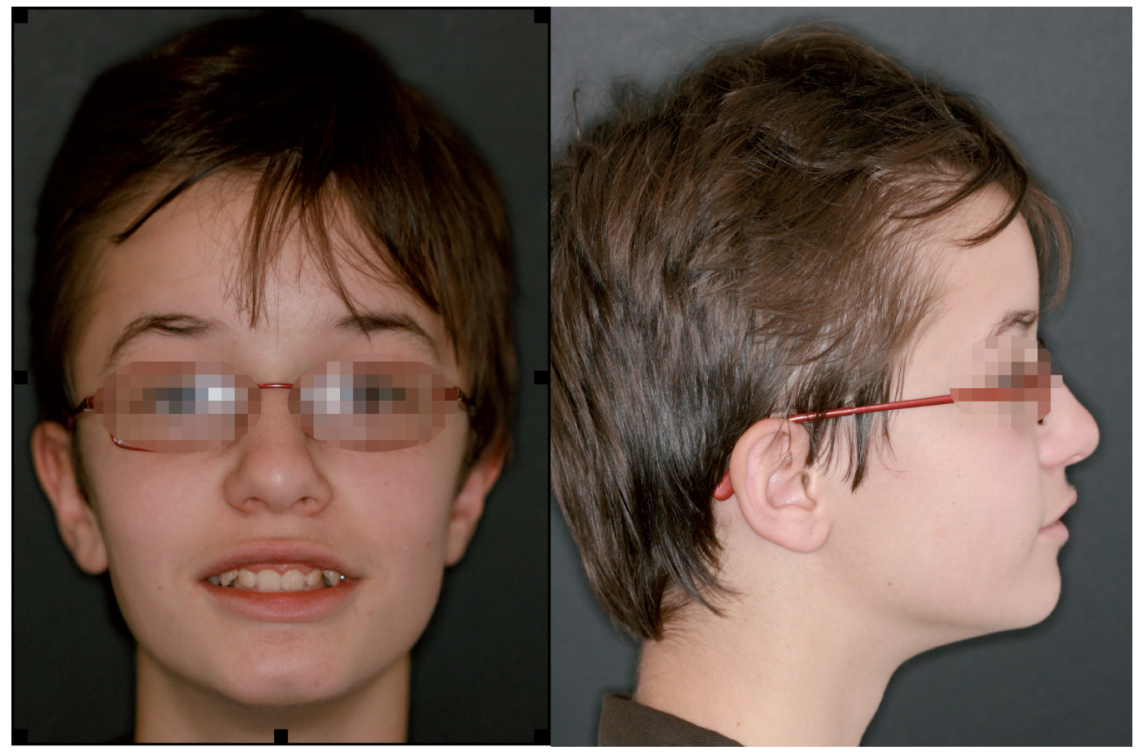

Figure 1

Brodie's Syndrome. Photos before treatment. have been described but they do not exclude simultaneous affliction of both arches, ${ }^{1,6}$. It should be noted that the maxilla is affected less frequently ${ }^{3}$.

Brodie bite can be found in 1 to $1.5 \%$ of the population (Fig. 1) ${ }^{16}$. Patients suffering from this syndrome have a Class I or Class II occlusion with either uni- or bilateral maxillary complete buccal crossbite ${ }^{19}$. Since there are no posterior occlusal contacts to be found, the premolars and maxillary molars are over-erupted and completely hide their antagonists (Figs. 2-3). In addition, a linguoversion of the lower molars is regularly seen along with an accentuated Curve of Wilson $^{16}$. Other clinical signs that can be found are a deficit in the transverse mandibular width, a reduction in the arch length and in the inter-canine width and a crowding in the mandibular incisor-cuspid area.
During the clinical examination, the practitioner must look for an occlusion in centric relation of the condyles in order to avoid a diagnostic error of a crossbite ${ }^{28}$. In effect, since the patients do not have a stable occlusal position because of the absence of molar contacts, a functional lateral crossbite can be presented. Study of dental casts is equally important, because it allows

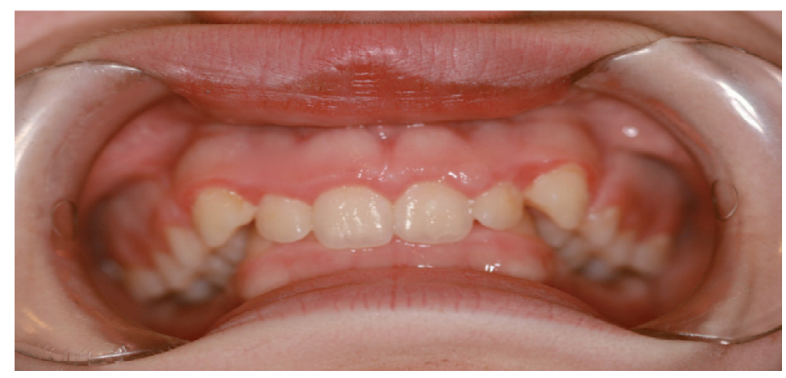

Figure 2

Brodie's Syndrome - Frontal view. Note the complete bilateral posterior crossbite. 

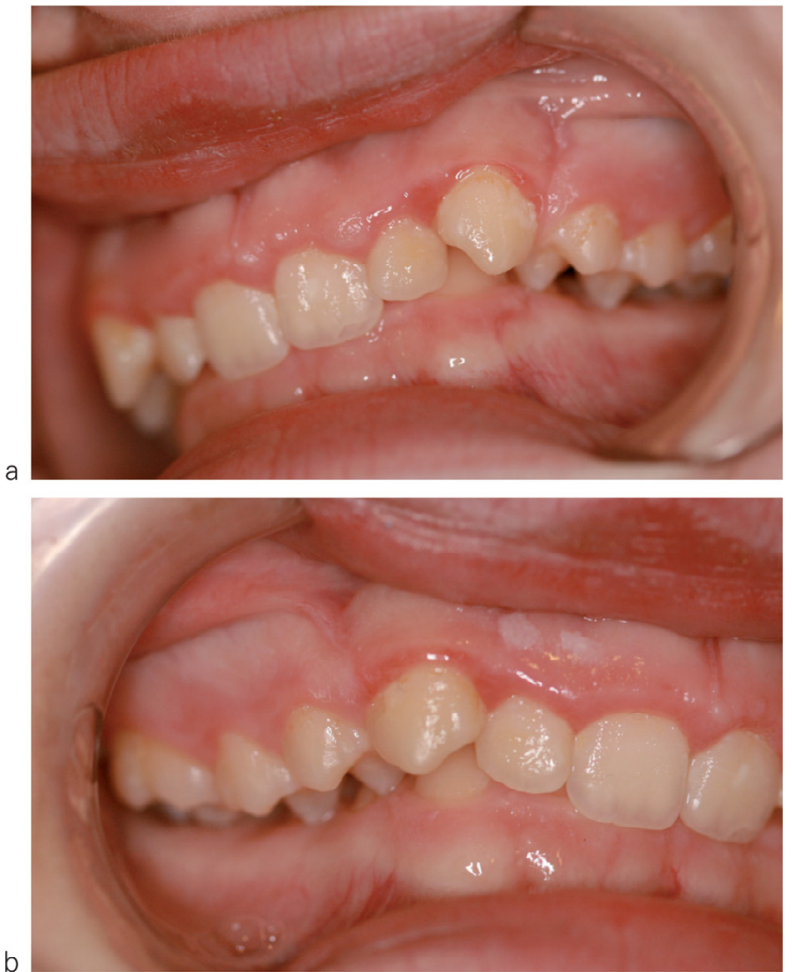

Figures $3 a \& b$

Brodie's Syndrome - Lateral views.

Note the complete crossbite with tissue contact, characteristic of Brodie's Syndrome. There is also a lack of oral hygiene.

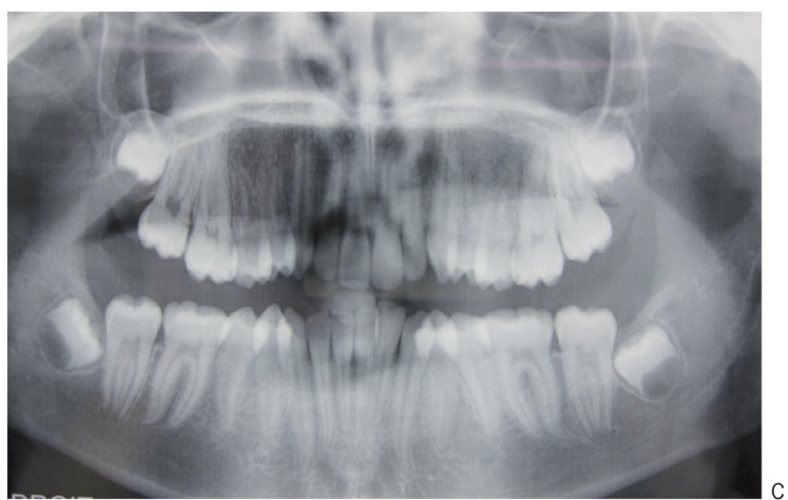

Figure 3c

Panoramic pre-treatment $x$-ray. Note the lower canine-to-canine crowding.

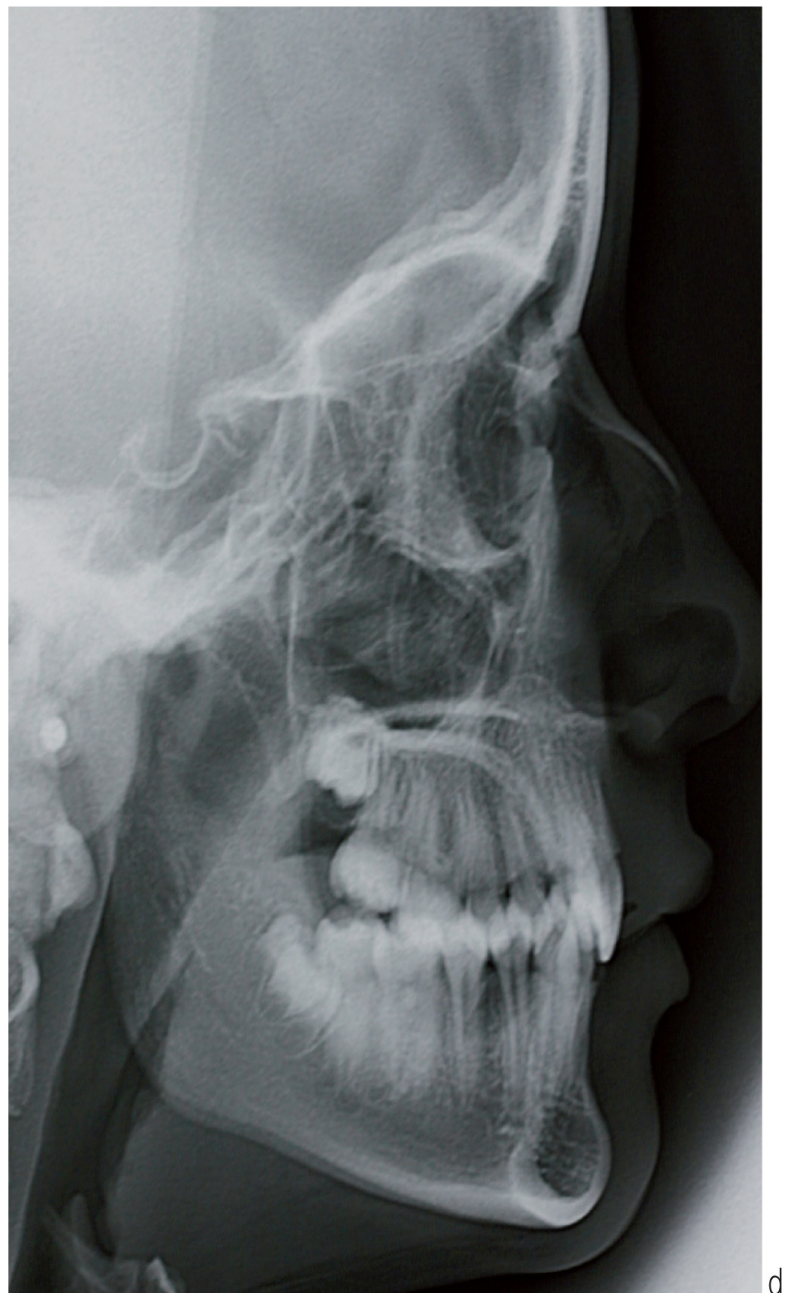

Figure $3 d$

Pre-treatment profile $x$-ray. Note an anterior deep bite with palatoversion (linguoversion) of the upper incisors, together they are characteristic of a Class II Brodie's Syndrome.

to check if simultaneous mandibular advancement will correct the abnormal transverse dimension ${ }^{8}$.

The main complaints of these patients are functional. This severe malocclusion leads to masticatory difficulties related to the absence of contacts but equally to interferences found during elocution movements. In addition, the over-eruption of the 
posterior teeth affects the periodontium and can injure the neighboring soft tissues, causing a not insignificant functional annoyance ${ }^{6}$.

\section{TREATMENT OPTIONS}

To correct the malocclusion, many treatment options were proposed. They include dental extractions, interproximal reduction and orthodontic compensation. The last option could damage the periodontium, particularly if there is a vestibuloversion of the lower anterior teeth, because it forces the teeth out of their alveolar bone ${ }^{14}$. Using intermaxillary elastics to create a vestibuloversion of the mandibular molars and a linguoversion of the maxillary molars also has a role in our therapeutic arsenal ${ }^{19}$. However, this leads to a non-physiologic interdental angulation. The problem with all of these therapies is that they allow dental and alveolar expansion without any bone augmentation in the mandible. Moreover, all the approaches to increase arch length and the mandibular intercanine width are often subject to relapse, as stipulated by Profitt"27. "Expansion" thus created is not only very unstable, but it also compromises the esthetics of the smile by modifying the black triangles of the buccal corridors $^{7,4,14,19}$.

Interproximal reduction has certain limits relating to the degree of correction that can be obtained. Since Brodie's Syndrome is a severe malocclusion, it is rare that one therapy alone will correct the problem. As for dental extractions, they make it possible to recreate satisfactory occlusal contacts, but often lead to a morphologic alteration that is not negligible ${ }^{10,21}$.

To treat the increased maxillary width, some authors have suggested palatal constriction, such as a segmental Lefort I osteotomy. This more delicate technique only allows for constriction of about five to six millimeters by resecting the bone between the segment. This approach risks damage to the palatal mucosa and creation of an oral-antral communication $^{3,4}$.

Other options are possible. For example, osteotomy to enlarge the mandible, as a treatment for a constricted mandible, is described. In fact, this surgery consists of a surgical separation at the mandibular symphyseal midline. Following, the fragments are positioned by rotational and translational movements at locations and are stabilized with the help of plates and screws. A bone graft is also necessary in order to fill the gap defect that is created at the osteotomy site. This technique has however been abandoned in light of the increased number of gingival dehiscences, of periodontal problems and of relapses ${ }^{4,8,11,25}$.

Since all these options present a number of disadvantages, such as instability or esthetic compromise, symphyseal distraction is an alternative treatment to consider in the correction of Brodie's Syndrome. 


\section{SYMPHYSEAL DISTRACTION}

This distraction technique is utilized in order to increase the transverse dimension of the symphysis. It presents a certain advantage when the dentoalveolar or skeletal anomaly cannot be corrected by traditional orthodontic therapies. These transverse deficits are found in an underdeveloped symphysis, in cases of significant lower incisor overlapping, in syndromic malocclusions such as Pierre Robin, Franceschetti and of course, Brodie's Syndrome 2,9,12,31.

Osseous distraction is a procedure that allows the creation of new bone between two osseous segments that are gradually separated by traction. The lengthening of the formed callus, or callotasis, is achieved progressively by daily activations of the distraction device. The mineralization of the callus is initiated after the third week following the end of activations (consolidation period) ${ }^{2,7}$.

\section{ASSESSMENT AND SURGICAL TECHNIQUE}

Given that mandibular symphysis fuses around the first year of life, the procedure of symphyseal distraction can be performed on a patient during the growth phase, as soon as the incisors and the permanent mandibular canines erupt, and on adults ${ }^{11}$. Before planning this type of surgery, a complete oral and dental examination is mandatory. Checking for any previous medical history, performing an occlusal dental analysis, assessing the periodontal health and the state of the temporal-mandibular joints,
At the beginning of the 1950s, Ilizarov described the technique of osseous distraction on long bones and extolled its many advantages for osteogenesis and tissue growth. McCarthy was the first to apply these principles on the human mandible in $1989^{24}$ and a few years later Guerrero used it in the correction of symphyseal transverse deficiencies $^{7,14,31}$. They noticed that the achieved expansion takes place not only in the alveolar bone, but also in the basal bone and surrounding soft tissues. In addition, they observed that the expansion created by symphyseal distraction was not proportionate, namely the expansion was greater in the canine areas than in the molar areas ${ }^{7,19,23}$. Because of this, due to the transverse and anterior-posterior growth achieved, there was an increase in the length of the arch and a change in its shape, going from a "V" to a "U" $U$ "7,9,11.

studying the moulages and taking xrays are all indispensable elements for preoperative evaluation. A panoramic xray makes it possible to assess the position of the dental roots. If significant dental crowding is also present, cone-beam is an invaluable tool for optimal visualization. Some authors have suggested that orthodontic treatment during the preoperative period needs to be started in order to create a divergence of the roots and/or a sufficient space near the osteotomy tract planned by the 
surgeon $^{10,21,26}$. These precautions make it possible to avoid injuries to the dental roots and the periodontal ligament, particularly if the available space is insufficient. Moreover, this fosters the formation and normal growth of a high quality bone. In fact, it has been shown that if the osteotomy leads to exposure of the root, the osseous formation cannot be achieved on the tooth. The presence of bone on both sides of the osteotomy is therefore desirable in order to optimally induce osteogenesis ${ }^{2,4}$. Besides, it is sometimes necessary to open the observed overbite of Brodie's Syndrome in order to allow for an expansion without occlusal interference. This can be achieved by the placement of molar bite raisers (bite turbos) ${ }^{6,9}$.

Symphyseal distraction can be done on an outpatient basis, with either general anesthesia or conscious sedation ${ }^{9,14,29}$. After injection of a local anesthetic, an incision from canine to canine through the mucosa and muscle of the oral vestibule is made using a cold or electric scalpel. A subperiosteal dissection follows on the anterior face of the symphysis until the mental foramina are visible. Identifying the dental apices makes it possible to direct the position of the distraction device. It must be positioned parallel to the ideal plane of distraction that in most cases, corresponds to the occlusal plane. In fact, since the connective tissue fibers inside of the callus are laid out parallel to the direction of the forces of distraction and since a translation movement is desired, it is important that the callus be as parallel as possible to the reference plane. In addition, the device must be placed very close to the point of resistance in order to achieve a symmetrical apposition. If this isn't the case, other force vectors will be induced with an asymmetrical osseous apposition and a rotation of the segments ${ }^{2,10,11}$. Therefore, it is of the utmost importance to pay particular attention to these details, because the placement of a distractor has an impact on the shape and the direction of the bone that will be created (Fig. 4).

Adapting the distraction device will be easier on a continuous mandible. Therefore, it is advisable to insert some screws to mark the ideal position once the symphyseal disjunction is completed. When the distractor is removed, a vertical osteotomy, beginning at the basal edge and stopping at the alveolar bone, is performed with a saw or a piezotome ${ }^{3}$. The use of osteotomies completes the symphyseal division between the dental roots (Fig. 5).

The scoreline is usually made between the two central incisors, but it can be off-centered in the parasymphysis in order to correct an asymmetry. It can also be shaped like a staircase step and still keep the cut centered on the basal bone, to diminish the risks of a dental defect or a lateral deviation of the chin $^{8}$. When the disjunction is completed, the distractor is put back into place using the holes already pierced into the bone as a reference. The distraction cylinder, that contains a telescopic screw, can now be joined to the plates of the device and activations are made to check proper functioning 


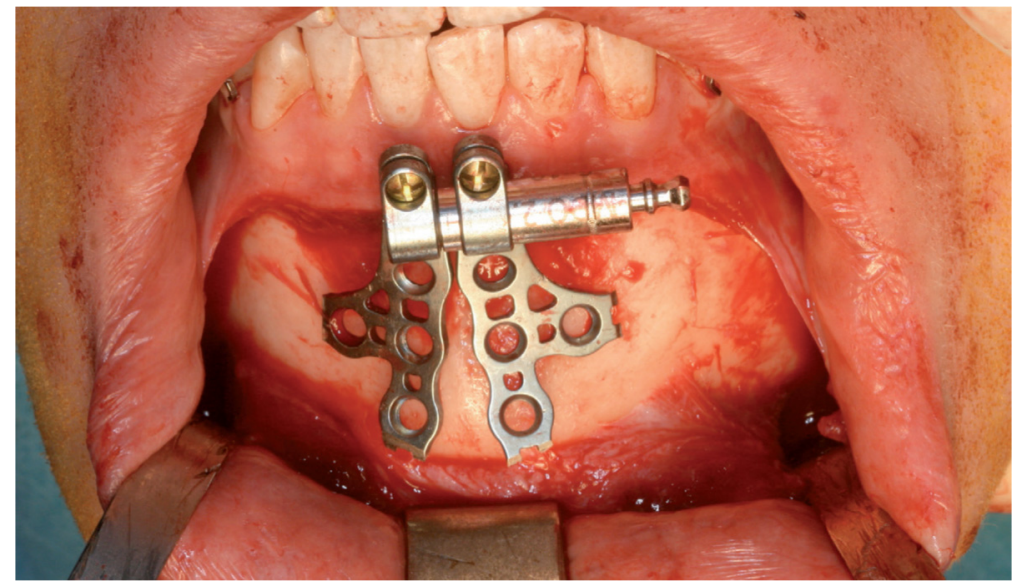

Figure 4

Fitting the distraction apparatus prior to the osteotomy.

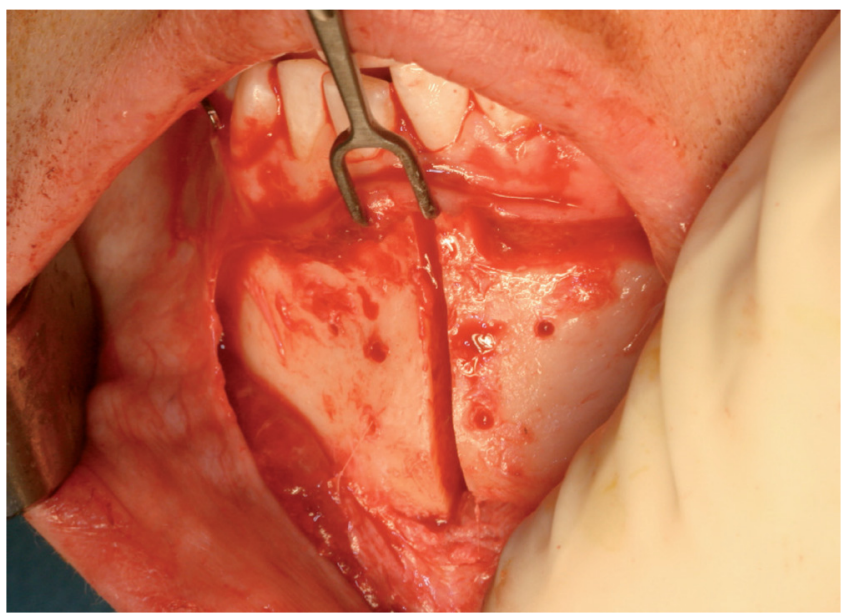

Figure 5

Complete vertical osteotomy tract.

Note the holes that serve as landmarks to relocate the distractor.

and to verify the vector of distraction. Next, the mucosa is sutured above

\section{DISTRACTION}

A few days after surgery, the distraction device can be activated. The the plates without however covering the cylinder (Fig. 6). latency period certainly allows for the creation of an osseous callus, but 


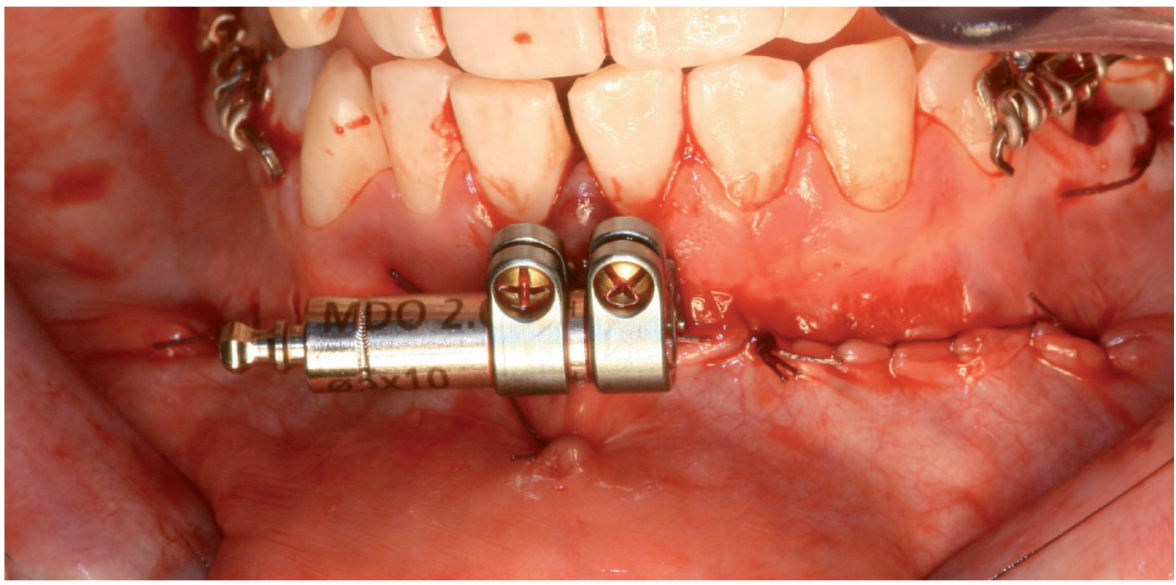

Figure 6

End of the operation.

also the healing of the mucosa. One or several activations can be prescribed, without however exceeding three millimeters a day. An excessively fast pace of activation lowers

\section{TYPE OF DISTRACTOR}

Several types of symphyseal distractors are on the market: distractors with dental supports, distractors with osseous supports and hybrid distractors, namely osseous and dental supports at the same time ${ }^{19}$. The dental distractor is usually attached to the lingual surface of the teeth and is the source of discomfort and hygiene problems. Moreover, its impact is more dentoalveolar than basal and it creates a labioversion of the lower incisors $2,11,18$. Because of this, the rate of relapse is increased since the alveolar expansion is not supported by the basal bone ${ }^{17}$. The difference in expansion can be explained by the position of the device the quality of the callus whereas a too slow rate of activation can lead to a premature osseous consolidation and therefore, an insufficient expan$\operatorname{sion}^{8,20,21}$.

that is above the point of resistance ${ }^{29}$.

A distractor with osseous supports is secured on the anterior osseous surface of the symphysis and chin. This distractor makes it possible to achieve a symmetrical distraction of the basal bone and of the alveolar bone since it directly transmits the forces of distraction to the mandible 8,29 .

However, in the course of distraction, the adjacent teeth migrate during callotasis if they are not orthodontically retained. This phenomenon called "walking-teeth phenomenon" is due to the elastic 


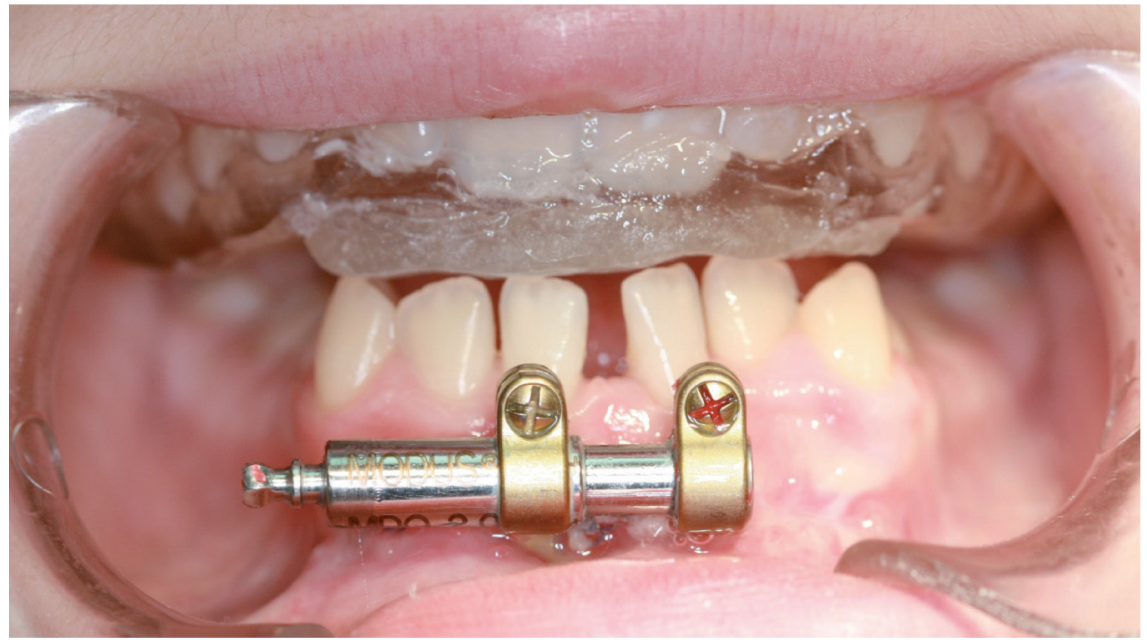

Figure 7

End of activations of the distraction appliance.

Note the presence of a removable device to open the deep bite.

traction of the transseptal fibers of the periodontal ligament ${ }^{2,14}$. Once the activations are stopped, a period of consolidation is necessary (Fig. 7).

Some authors recommend maintaining this phase for two months before beginning orthodontic movements. Before the end of the period of consolidation, they recommend that the practitioner use xrays to check the quality of the osseous callus formation. They stipulate that an

\section{ADVANTAGES OF THE TECHNIQUE}

Symphyseal distraction as a treatment for Brodie's Syndrome, has a number of advantages.

Since it is reliable and safe, it allows for osseous expansion as well as expansion of soft tissues such as muscles, subcutaneous tissues, free and attached gingiva ${ }^{12,16}$. This versatile surgical technique can be early movement can lead to a periodontal defect, an osseous defect and even the loss of a tooth $8,11,13,14$. Whereas others advocate an early reactivation, namely from 5 days to 2 weeks following the end of the activations of the device $3,4,11,23,29$. Liou suggests that the orthodontist initiate orthodontic movements early because the forces created accelerate the maturation of the fibrous bone that is produced ${ }^{22}$.

adapted to any defect including the three axes (anterior-posterior, transverse and vertical) $)^{13}$. In addition, it allows for the extraction of the wisdom teeth, genioplasties and concurrent expansion of the upper maxillary 9,11,14,21. Minimally invasive, this short-term procedure is predictable and does not require any bone 
grafting and therefore entails no morbidity at the donor site $7-9,13$. Symphyseal distraction eliminates extractions and compensatory vestibuloversions, and allows the practitioner to harmonize the arch and at the same time diminishes the risk of relapse and periodontal complications ${ }^{9,13}$. Of course, there may be mobility of the teeth close to the osteotomy site secondary to inflammation, but it is temporary ${ }^{11,16}$. Moreover, one of the advantages of this therapy is that orthodontic treatment can be simultaneously performed with anterior distraction. Furthermore, no long-term neuro-sensory damage has been reported $^{13,29}$.

However, this technique has some disadvantages. The placement of the distractor requires a second surgery for its removal and quite obviously additional costs are involved for its purchase $^{10,30}$. Even if these studies show that the risk is low, there is always the possibility of damaging the adjacent teeth. In addition, wearing the device can trigger chronic gingivitis $^{15,29}$. Questions remain as to the effect of symphyseal distraction on the temporomandibular joints. To begin with, it appears that the condyle moves differently based on the type of distractor used. Del Santo et al. suggest that when a teeth-supported distractor is used, it increases the inter-condylar distance. However, results are not statistically significant ${ }^{11}$. For their part, Molkoç et al. and Landes et al. argue that there is a decrease in this distance with hybrid bone-supported distractor ${ }^{20,23}$. Nonetheless, temporomandibular condyles adapt easily to lateral and median movements given that only temporary symptoms of temporomandibular joint dysfunction have affected a few patients $5,11,15,23$. A study on monkeys demonstrated that minor histological changes occurred in the different layers of the condyle, particularly in areas of compression. These zones, located on the posterolateral and on the antero-median surfaces of the condyle constitute, in fact, an adaptive response to the rotation of the condyles ${ }^{2}$. To date, no notable repercussion has been found in any of the reported studies.

\section{CONCLUSION}

Even if Brodie's Syndrome is not a common malocclusion, it is important to know all the available therapeutic options to improve patient's occlusion, function and esthetics.. Symphyseal distraction has proven to be a highly recommended treatment solution given its many advantages, particularly concerning osseous growth and periodontal preservation (Figs. 8-10). 


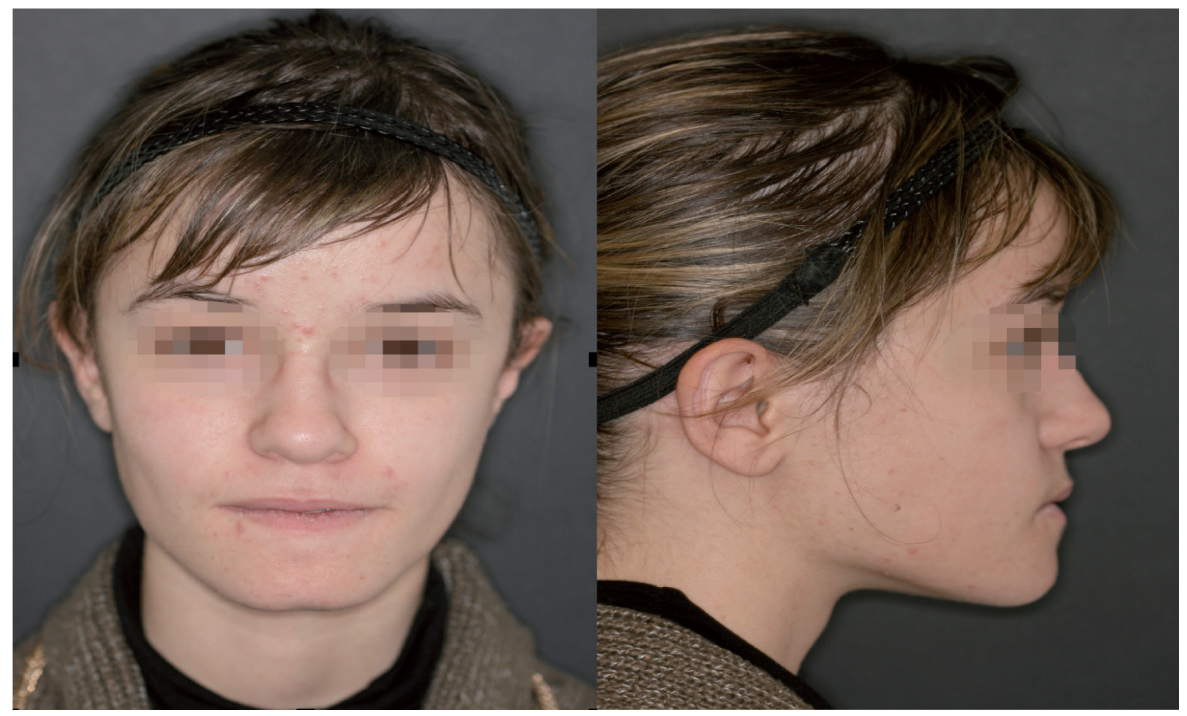

Figure 8

Brodie's Syndrome.

End of Treatment photos.

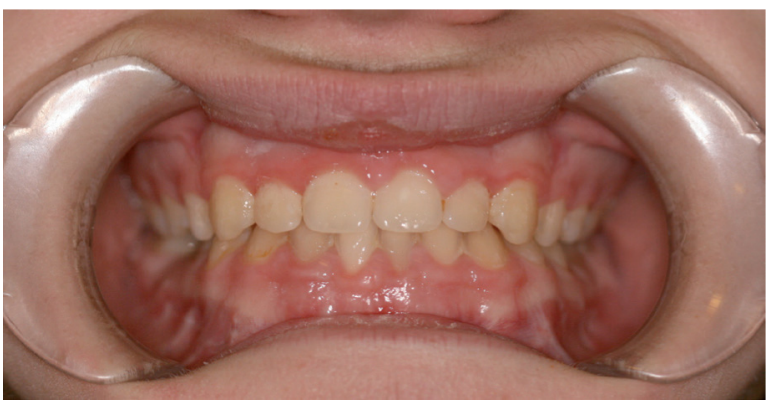

Figure 9

Frontal view of occlusion at the end of treatment.
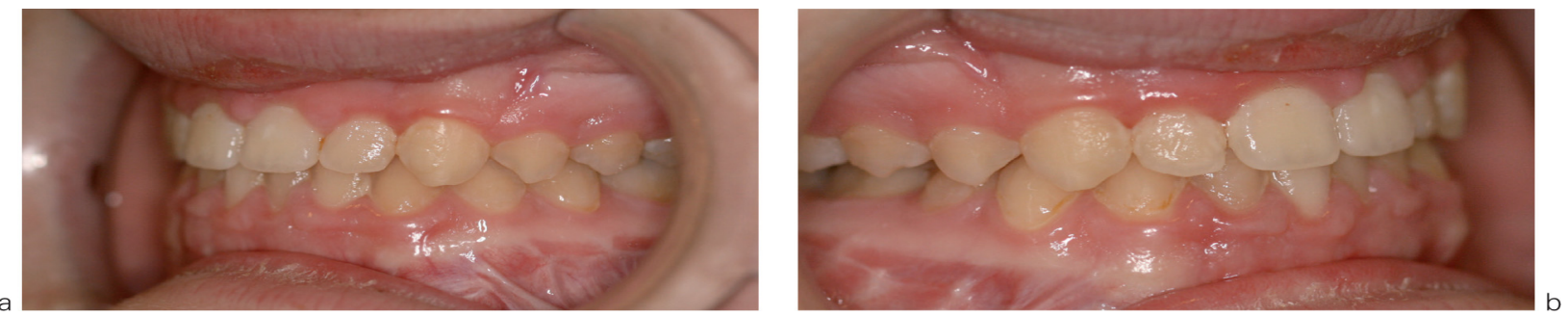

Figures 10a \& b

Lateral views of occlusion at the end of treatment.

We found a Class I canine and molar as well as a normalization of the transverse posterior occlusal relationships. The overbite has been raised. Unfortunately, the hygiene remains inadequate. 


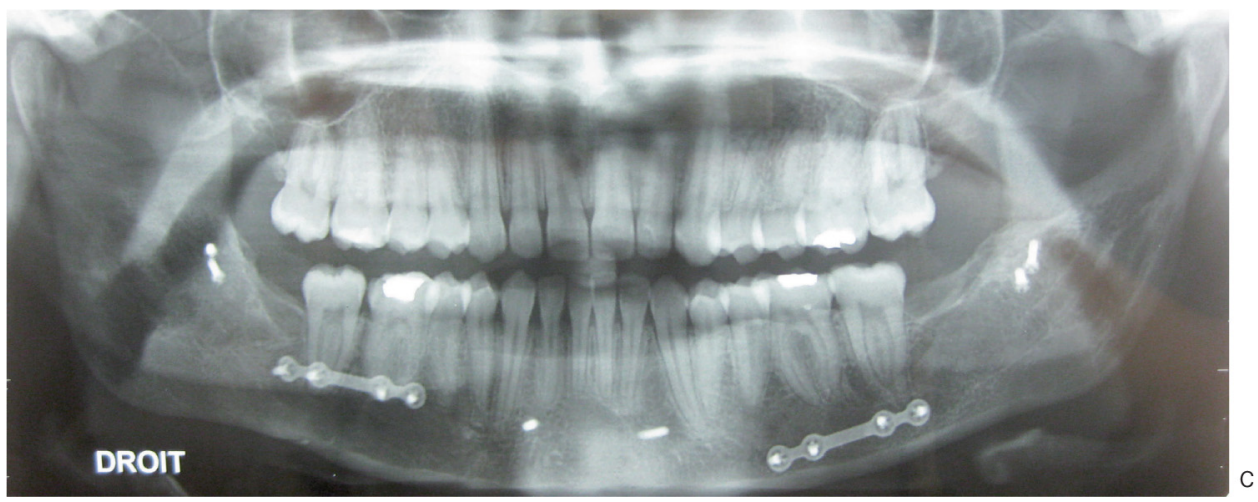

Figure 10c

Panoramic $x$-ray after treatment. We found classical osteosynthesis along with two residual screws, in the syphyseal area, that could not be removed because of a complete osseous integration. It is noted that the patient had to undergo a sagittal osteotomy of the ascending ramii in order to correct his mandibular retrusion.

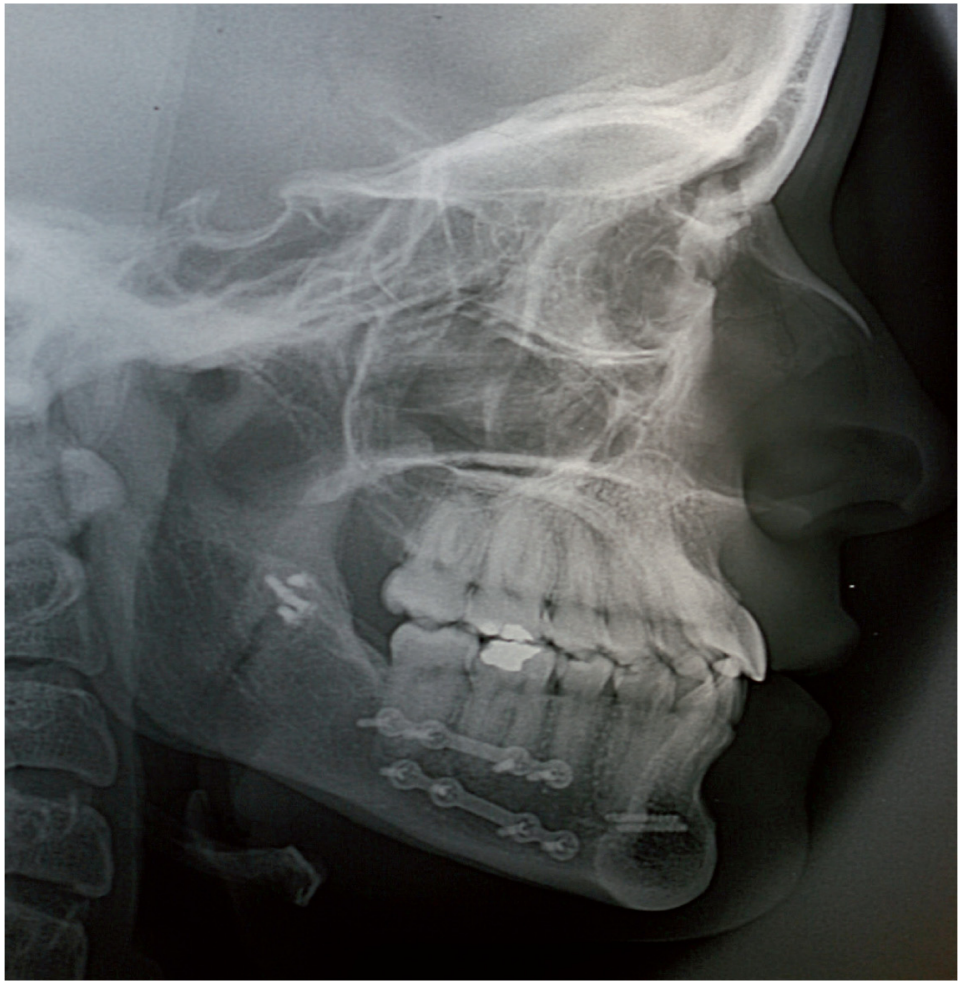

Figure $10 d$

Post treatment profile xray. The overbite has been leveled and the normalization of the basal bone was completed by a bilateral sagittal osteotomy of the ascending ramii. 


\section{REFERENCES}

1. Bassigny F. Signes majeurs et signes associés des anomalies orthodontiques. Sémiologie orthodontique, EMC - Odontologie/Stomatologie/Orthopédie Dentofaciale 2012;7(4):1-16.

2. Bell WH, Harper RP, Gonzalez M, Cherkashin AM, Samchukov ML. Distraction osteogenesis to widen the mandible. Brit J Oral Max Surg 1997;35:11-9.

3. Beziat JL. Chirurgie de la dimension transversale. Orthod Fr. 2011;82:159-69.

4. Bouletreau P, Paulus C. Surgical correction of transverse skeletal abnormalities in the maxilla and mandible. International Orthodontics 2012;10:261-73.

5. Braun S, Bottrel JA, Legan HL. Condylar displacement related to mandibular symphyseal distraction. Am J Orthod Dentofac Orthop 2002;121:162-5.

6. Chugh VK, Sharma V, Tandon P, Singh GP. Brodie bite with an extracted mandibular first molar in a young adult: a case report. Am J Orthod Dentofac Orthop 2010;137:694-700.

7. Chung YW, Tae KC. Dental stability and radiographic healing patterns after mandibular symphysis widening with distraction osteogenesis. Eur J Orthodont 2007;29:256-64.

8. Conley R, Legan H. Mandibular Symphyseal Distraction Osteogenesis: Diagnosis and Treatment Planning Considerations. Angle Orthod 2003;73:3-11.

9. Contasti GI, Rodriguez AM, Guerrero CA. Orthodontic Mandibular Widening by Distraction Osteogenesis. Orthodontic Cyber Journal 1998;12.

10. Del Santo M, English JD, Wolford LM, Gandini LG. Midsymphyseal distraction osteogenesis for correcting transverse mandibular discrepancies. Am J Orthod Dentofac Orthop 2002;121(6):629-38.

11. Del Santo M, Guerrero CA, Buschang PH, English JD, Samchukov ML, Bell WH. Longterm skeletal and dental effects of mandibular symphyseal distraction osteogenesis. Am J Orthod Dentofac Orthop 2000;118:485-93.

12. Ferri J, Movaghar R, Sebille S. La distraction ostéogénique en chirurgie orthopédique de la mandibule. Orthod Fr 2005;76:287-95.

13. Guerrero CA, Bell WH, Contasti GI, Rodriguez AM. Intraoral mandibular distraction osteogenesis. Semin Orthod 1999;5:35-40.

14. Guerrero CA, Bell WH, Contasti GI, Rodriguez AM. Mandibular widening by intraoral distraction osteogenesis. Brit J Oral Max Surg 1997;35:383-92.

15. Gunbay T, Akay MC, Aras A, Gomel M. Effects of Transmandibular Symphyseal Distraction on Teeth, Bone and Temporomandibular Joint. J Oral Maxillofac Surg 2009;67:2254-65.

16. Harper Dennis L. A case report of a Brodie Bite. Am J Orthod Dentofac Orthop 1995;108:201-6.

17. Herberger RJ. Stability of mandibular intercuspid width after long periods of retention. Angle Orthod 1981;51:78-83.

18. Hollis BJ, Block MS, Gardiner D, Chang A. An experimental study of mandibular arch widening in the dog using distraction osteogenesis. J Oral Maxillofac Surg 1998;56:330-8.

19. King JW, Wallace JC. Unilateral Brodie Bite treated with Distraction Osteogenesis. Am J Orthod Dentofacial Orthop 2004;125(4):500-9.

20. Landes CA, Laudemann K, Sader R, Mack M. Prospective changes to condylar position in symphyseal distraction osteogenesis. Oral Surg Oral Med Oral Pathol Oral Radiol Endod 2008;106:163-72.

21. Lesne B, Bettega G, Morgon L, Aknin JJ. Distraction symphysaire et orthodontie. Orthod Fr 2008;79:197-207.

22. Liou EJ, Figueroa A, Polley JW. Rapid orthodontic tooth movement into newly distracted bone after mandibular distraction osteogenesis in a canine model. Am J Orthod Dentofac Orthop 2000;117:391-8. 
23. Malkoç S, Iseri H, Karaman A I, Mutlu N, Küçükkolbasi H. Effects of mandibular symphyseal distraction osteogenesis on mandibular structures. Am J Orthod Dentofac Orthop 2006;130:603-11.

24. McCarthy JG, Schreiber J, Karp N, Thorne CH, Grayson BH. Lenghtening the human mandible by gradual distraction. Plast Reconstr Surg 1992;89:1-8.

25. Mommaerts MY. Bone anchored intraoral device for transmandibular distraction. Brit J Oral Max Surg 2001;39:8-12.

26. Mommaerts MY, Polsbroek R, Santler G, Correia P, Abeloos J, Ali N. Anterior transmandibular osteodistraction: clinical and model observations. J Cranio Maxill Surg 2005;33:318-25.

27. Profitt WR, Ackerman JL. Current principles and techniques. 2nd ed. Philadelphia: Mosby-Year Book, 1994.

28. Raberin M. Pathologies et thérapeutiques de la dimension transversale en denture mixte. Conséquences sur l'équilibre musculaire. Orthod Fr 2001;72:131-42.

29. Raoul G, Wocjik T, Ferri J. Outcome of mandibular symphyseal distraction osteogenesis with boneborne devices. J Craniofac Surg 2009;20:488-93.

30. Sukurica Y, Gurel HG, Mutlu N. Six year follow-up of a patient treated with mandibular symphyseal distraction osteogenesis. J Craniomaxillofac Surg 2010;38:26-31.

31. Vereecke F, Caprioli F, Raoul G, Bennani K, Ferri J. Prise en charge des déficits transversaux antérieurs de la mandibule par ostéodistraction symphysaire. Résultats préliminaires á propos de trois cas cliniques. Ann Chir Plast Esthet 2001;46:304-15. 